clined to pass more or less liquid stools, a complication which was said to be 'tolerable' in some and to cause ' serious disability' in a few. All of these patients had before operation habitually passed fluid motions and it was felt that such a history should encourage one to take great pains to avoid a colostomy.

Although most of the opinions mentioned above have been given as evidence in support of the radical types of operation, it can be fairly concluded that the lot of the average colostomy patient is by no means an unhappy one, and that an alternative operative procedure which attempts to spare him this disability must not be allowed in any way to diminish his chances of continued survival.

\title{
THE RELIEF OF PAIN
}

By A. J. GlazebrooK, M.D., M.R.C.P., and Fred Wrigley, M.R.C.S., D.I.H., M.P.S.

'Pain is perfect misery, the worst

Of evils; and, excessive, overturns

All patience '-(Milton).

A drug which afforded complete relief from pain without other action would be an inestimable boon to humanity. Pain has always been the predominating symptom in diseases of man; it is therefore not surprising that the science of analgesia is of great antiquity. References to it are found in all the early schools of medicine, the Chinese in 500 B.C. and afterwards in the Persian, Indian and Greek. Preparations were made from mandrake, hellebore, poppy, hemlock, henbane, mulberry, lettuce and hops, and while the concoctions were made heroic they were often useful.

During the dark period of the Middle Ages the art of medicine fell into the hands of the Church, and no advances in analgesia were made; indeed, uncertainties as to the preparation of opium mixtures often led to fatalities. This, coupled with religious objections, caused them to fall into disuse. In the I th century we find Nicholas Bailly, a French barber surgeon, being accused of witchcraft because he prescribed opium, and a law was passed in France banning its use.

In course of time opium came to be recognized as the only potent analgesic and it retained this place until comparatively recently. Sydenham said that without opium the healing art would cease to exist, and while this is not true today there can be few doctors who would care to be without it or its derivatives for their practices.

The first real step forward since the time of the Greeks was the isolation by Sertürner (1806) of morphine and the recognition that it was the main analgesic alkaloid in opium. This isolation of the alkaloid enabled standardized preparations to be made which could take the place of the unreliable tinctures previously used. More confidence could be placed in the prescription of the drug and its clinical applications were increased.

In 1876 MacLagan argues that as quinine was? obtained from the cinchona tree found in malarial areas, nature would undoubtedly provide a specific for rheumatism in areas notorious for this complaint. This led him to investigate extracts of the willow, and in this way he hit upon salicin. The fact that salicylates had analgesic properties was soon seen, and in 1889 aspirin was produced commercially and rapidly became a household analgesic and antipyretic. Further research into aniline derivatives produced an impressive array of painrelieving compounds, the two most important groups being those derived from aniline and the closely-related phenetidin such as acetanilide and phenacetin, and those derived from pyrazol such as antipyrin and amidopyrin. Aspirin administration has recently been helped by the discovery of a stable soluble calcium salt.

All of these products have an undoubted paindulling action, but the extent of it is not to be compared with that obtained by the opiates. In view of their relatively weak analgesic action, Fourneau (1938) suggested that they be separated from true analgesics and called antalgics. Until quite recently they furnished the only class of totally synthesized pain relievers.

Attempts were also made to improve opium and morphine preparations. These took two main lines-the purification of opium to obtain a 
product with all of its alkaloids intact and the treatment of morphine to make, by part synthesis, closely related compounds.

Sahli (1909) prepared the first compound containing the total opium alkaloids free of gums, resins and other inert and irritating ingredients. In Britain this came to be known as 'Omnopon.' Its main advantage over morphine is that it is less likely to cause smooth muscle spasm. 'Omnopon,' incidentally, formed the first successful intravenous preparation of opium alkaloids, although Sir Christopher Wren, assisted by Boyle ( $\left.165^{6}\right)$, had injected opium experimentally into the veins of dogs.

Part synthesis from morphine and related alkaloids and separation of the naturally occurring alkaloids in opium led to the production of compounds such as dionin, heroin, dilaudid, dicodid, apomorphine, metapon and the naturally occurring codeine. These products all vary greatly in analgesic action, toxicity and power to cause the development of addiction or tolerance. Apomorphine, for instance, is used clinically in $5 \mathrm{mg}$. doses for its emetic effect, its mild analgesic action being valueless, whilst metapon, in doses of 6 to $9 \mathrm{mgm}$., has a powerful analgesic action with fewer side effects than morphine, attributes which have gained a certain popularity for it in the United States.

However it was Sertürner's isolation of morphine which had really set the stage for the fascinating but laborious work of chemical detection which now followed. Clearly the next step was to establish the chemical structure of morphine. If this could be done it might then be possible to track down that portion of the morphine molecule responsible for its analgesic action and produce a substance with enhanced therapeutic power and diminished side effects.

The structure of morphine proved to be exceedingly complex, but it is generally accepted. today that it is an arrangement of five rings in a spatial relationship of three dimensions, and eventually it came to be realized that the rupture of one of these, the piperidine ring, led to an almost complete loss of analgesic power.

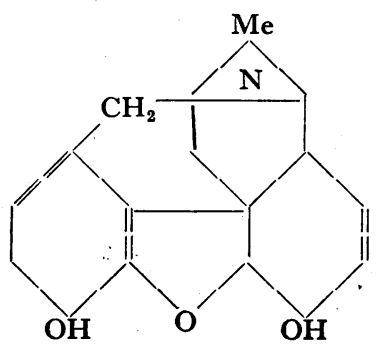

Morphine
In 1938 one of those curious and completel accidental discoveries which occur so frequently in medicine was made and suddenly illuminated the whole field of analgesic research. Eisleb and Schaumann, while performing toxicity trials on new spasmolytic drug dolantin (ethyl 4-phenyl-1 methylpiperidine-4-carboxylate) discovered that caused tail erection in the test animals, 8 phenomenon described by Straub (I9II) as oc curring in animals given morphine. This acute observation led directly to the testing and estab lishment of dolantin (pethidine, demerol) as an analgesic, and the realization that pethidine in it structure of a 4-phenyl piperidine derivative, cong stituted a fragment of the morphine molecule.

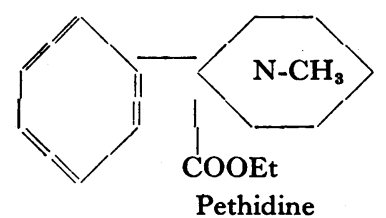

This chance discovery of the first true syntheti analgesic led to many attempts to modify its simple structure in all possible ways, and some promising analgesics were produced.

It might have been thought that the chaptes which had opened with the isolation of morplone was now concluded, from the analgesic activity of certain of the 4-phenyl piperidine derivatives suct as pethidine, and the known loss of analgesio potency brought about by the opening of th\% piperidine ring in morphine, and that the piperidin 8 ring was an essential feature of an analgesic.

Further work, however, in subjecting the morphine molecule to intensive dissection pro? vided the framework of many new compounds? some of which were found to possess analgesis properties. In the diphenylpropylamine class the most potent was found to be the ketone first rej ferred to as Hoechst 10820 (B.I.O.S., 1945) with the following constitution:-

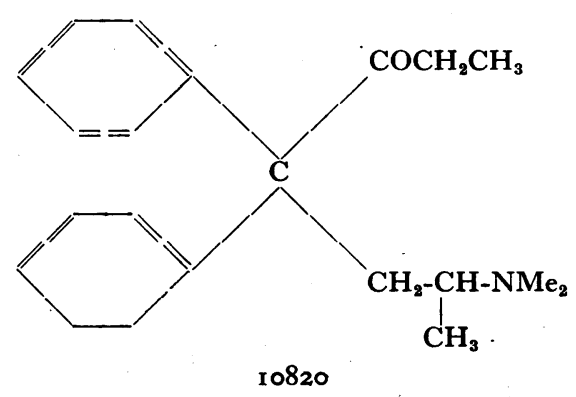

It can be seen that this powerful analgesic i contrast to pethidine and morphine does not possess 
a piperidine ring. It is now produced commercially and known variously as amidone, physeptone, miadone, dolophine, methadon, etc. A closely related compound is phenadoxone (Wilson and Hunter, 1948).

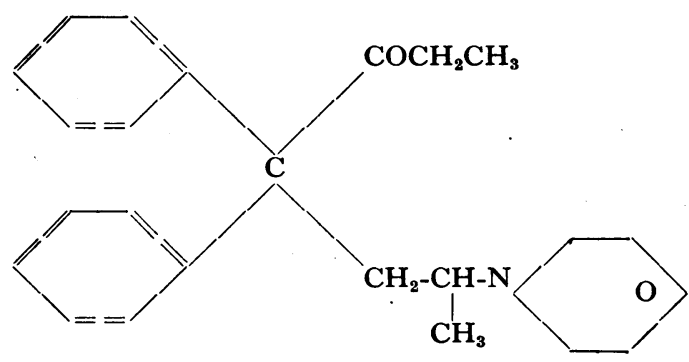

Phenadoxone (Heptalgin, Compound C.B. I I, Heptazone)

Although at first sight the molecule of the diphenylpropylamine derivatives (represented by amidone and phenadoxone) is markedly different from that of the 4-phenyl piperidines (represented by pethidine) and the natural prototype morphine, when an atomic model is made the structural similarity of amidone and pethidine to morphine becomes apparent. Thus Bergel and Morrison (1948) have concluded that the shape or fit of the molecule as a whole is more important in determining its analgesic activity than any one duplication of precise fractions of the morphine molecule.

\section{Properties and Mode of Action of Analgesics}

All of the well-established analgesics have strongly basic properties which make possible their parenteral injection in the form of water soluble salts. Pharmacologically they are considered to belong to the class of symptomatic drugs having a depressant action on the central nervous system. There is some doubt as to whether they interfere with the oxygen uptake of nervous tissue; the balance of evidence is against this assumption (Elliott, 1947). The hypothesis that analgesics specifically block certain metabolites essential for the central nervous system, such as amino acids, awaits further proof. They differ from members of other groups such as anaesthetics, sedatives and anti-epileptics in that they abolish or diminish the sensation of pain without causing stupefaction or loss of consciousness. In non-toxic quantities they do not lower the threshold for touch, vibration sense, two-point discrimination, smell or hearing.

\section{Methods of Testing Analgesic Action}

There are several methods of testing the analgesic power of drugs in animals and in human beings, all relying on the comparison with mor- phine or some other substance such as pethidine, the clinical value of which is known.

I. Small rodents sit up and blow on their paws when a plate on which they are placed becomes uncomfortably warm.

2. This method has now been superseded by one which employs a heated wire at the base of the animal's tail. The animal is free to move the tail and does so when the wire becomes unpleasantly warm (Davies, Raventos and Walpole, 1946).

3. The concentration of a light beam on to the shaved back of a guinea pig. As soon as the heat is felt twitching of the skin is observed. The length of time before the twitch takes place can be increased by the administration of analgesics.

In humans various methods employ the pain of mechanical, thermal or electrical stimulation of the skin or gums, or of artificially-produced muscle ischaemia (Hewer and Keele, I948). The Hardy Wolff Goodell technique (r940) is the best known. In this method a standardized source of radiant heat is applied to a black painted patch on the forehead of the tested subject. The technique has been elaborated and degrees of pain can now be measured in 'dols,' which allows a critical evaluation of the analgesic effects of various drugs.

Too much reliance must not be placed on such methods. Results obtained in animal experiments are not applicable to man, for various animal species exhibit varying sensitivity to differento analgesics. Moreover, in evaluating the relative? potencies of drugs, unless the log-dose-response graphs are parallel, the ratio will vary for all dose levels and it will be impossible to predict which dose level in an animal is equivalent to a clinical dose in man. Nevertheless, these screening tests in animals do help to guide chemical research and spare clinical trials.

In man so many factors enter into the determination of the suitability or otherwise of a drug that only prolonged clinical trials are really of value as a final means of assessment. For further consideration of the value of analgesic tests the reader is referred to "Recent Advances in Pharmacology' (Robson and Keele, 1950).

\section{Toxicity}

The side effects from the new potent analgesic drugs consist of respiratory depression (Prescott et al., 1949) with subjective symptoms of sweating, pallor, dizziness, vertigo, 'swimmy feelings in the head,' drowsiness, nausea and vomiting, which may be so severe and prolonged that profound prostration is caused.

Rarer side effects are the occurrence of pruritus and of hyperalgesia. This last phenomenon is an odd and unexpected manifestation which has been noted to occur for a few minutes after the ad- 
ministration of amidone, to be followed later by analgesia (Glazebrook, loc. cit.). It may be related to the observations made by Elliott (1947), who claimed that morphine and pethidine inhibited tissue respiration in brain slices, whereas amidone in low concentrations caused stimulation followed later by inhibition.

Pethidine does not cause respiratory depression but brings about a lowering of the blood pressure (Scott, Robins and Chen, 1946).

The side effects are more pronounced when the drugs are given parenterally. It would seem that the more potent the analgesic the greater the magnitude of these effects. This unfortunate tendency has been a hindrance to the development of some promising products.

The more depressing side effects tend to be delayed. A common sequence is a sensation of slight dizziness about ten minutes after injection when the analgesic action is beginning to be felt. This rapidly passes off, being followed by sweating and pallor for a short time, then by severe symptoms of nausea or vomiting as a late manifestation four to eight hours after injection. The delay in these later symptoms suggests that they are due to breakdown products.

The side effects are much less marked if the patient is recumbent. In some patients a liability to these toxic effects can be abolished by giving subtherapeutic doses for a day or two before and increasing it gradually to a full dose. In others this manoeuvre is not successful even if persisted in for weeks.

\section{Addiction}

The most undesirable action of the opium derivatives is their ability to cause addiction. This factor has been kept constantly in mind during the search for better analgesics in the hope that one will eventually be found free of this trait.

Addiction may be defined as the almost insatiable desire for often repeated doses of a substance which cannot be controlled by reasoning. Any analgesic which produces euphoria must be suspected as a drug of addiction, and probably the amount of euphoria produced by any drug is related to its power to produce addiction. Here we must be careful to differentiate between the patient in great and constant pain who feels a need for a drug for pain relief and the patient who demands it because of the sense of well-being which it produces.

After a patient has taken a true drug of addiction for some time his cellular metabolism becomes disturbed because of the constant presence of the drug and eventually his tissues come to function well only if the drug is present. The patient is now dependent upon it, his tissues crave it and the $\varrho$ problem is a much greater one than that of simple $\frac{3}{\Phi}$ deprivation of a favourite tipple, for withdrawal 은 symptoms can be very severe and prostrating. Cases have been recorded in which babies have $\stackrel{\vec{s}}{\vec{S}}$ been born drug addicts, their tissues demanding $\overrightarrow{0}$ the presence of the drug just as clamantly as those 드 of their drug-addicted mothers (Perlstein, 1947).

Certain drugs are better euphorigenics than they $\mathbb{\Omega}$ are analgesics. . Cannabis indica, for instance, undoubtedly has a low analgesic activity, but is $\rightarrow$ capable of producing marked euphoria, and this is? also true of the synthetic cannabis preparation $\vec{\omega}$ 'Synhexyl' (Parker and Wrigley, 1949, 1950). ${ }^{\omega}$ Extracts from natural cannabis have been classified with the morphine alkaloids under the Dangerous 3 Drugs Act.

There is a tendency at first for all new potent analgesics to be considered non-habit forming.. Heroin, for instance, produced by acylation of the morphine molecule, was put out in great hopes $\bullet$ and acclaimed as being free of any such tendency, 을 but soon after its introduction this powerful and $\vec{Z}$ toxic drug became a favourite of the drug addicts $Z$ of the world. Codeine, on the other hand, $a \Phi$ naturally occurring methyl ether of morphine, ds $\bar{\sigma}$ relatively safe, but has lost much of the analgesjic power of its parent substance.

Pethidine is euphorigenic and for this reasmo alone will produce habit formation in susceptible subjects. However, the cellular metabolism is not? disturbed to the degree found in morphine addicts. Discussing pethidine addiction Polonio (1947) states 'physical dependence on the drug is noto great and all authors are agreed on the mildness of the withdrawal syndrome.' $\beta$-Pethidine (Glaze-o을 brook and Branwood, I945), a very closely re- $\frac{3}{2}$ lated compound, produces much less euphoria than pethidine, but also has less analgesic activity. Another 4-phenyl piperidine derivative, $N u$ 896, $\frac{3}{3}$ has very powerful analgesic powers, much moreso than pethidine, but it also has marked euphori- 3 genic properties, patients becoming very lively: and talkative after its injection (Glazebrook, loc. cit.).

Amidone undoubtedly produces euphoria, although to a lesser extent than $N u$ 896. This subjective reaction has been described by former morphine addicts as entirely. comparable to that ${ }^{\mathrm{O}}$ experienced with morphine. Most commonly $N_{0}$ these addicts describe the effects of amidone as very N like those produced by heroin, especially wheno amidone is given intravenously. There is proro duction of tolerance to all of the morphine-like effects, and withdrawal symptoms, differing from? those of morphine in time relationship and in- $\bar{T}$ tensity, but definite and characteristic, can be $\underset{\mathbb{D}}{\stackrel{0}{D}}$ 
produced (Commission on Narcotic Drugs, I948).

Phenadoxone has similar euphorigenic properties.

It can be said that in spite of the intensive research of the past ten years no good analgesic has been produced entirely free of the dangers of addiction, and where temporary control of pain is needed geat caution must be exercised in prescribing these drugs. Pethidine and codeine are the safest from this point of view; next are amidone and phenadoxone, and lastly morphine and heroin, the latter probably being the most dangerous.

It is also well to bear in mind at this stage that the production of euphoria is not necessarily a bad thing; indeed, it may confer a priceless boon both to a pain-racked, depressed patient and the harassed and anxious attendants to replace listlessness and apathy with brightness and an urge for conversation. The dangers of addiction may be ignored in the incurable case dying of malignant disease; indeed, it is difficult to understand the attitude of those who would deprive such people of the merciful relief to be obtained from potent analgesics on the grounds of habit formation.

\section{Other Side Effects}

The subjective side effects produced by aspirin and the salicylates in analgesic dosage are, of course; practically nil and this drug has become a household remedy because of its safety and innocuousness. The introduction of the stable soluble calcium salt has greatly improved its therapeutic efficacy and lessened the chance of gastric upset.

Salicylates in the large doses used for the control of acute rheumatism, e.g. I 50 gr. daily and over, depress the prothrombin level of the blood and encourage a haemorrhagic tendency, sometimes even giving rise to haematemesis. For this reason preparations of aspirin with vitamin $\mathrm{K}$ have been put out by pharmaceutical houses. The lowered prothrombin level which follows large doses of salicylates may be of therapeutic value (Glazebrook and Cookson, 1947; Wrigley, 1948). The prescribing of alkali with salicylate is probably useless because all that the alkalies do is to increase the excretion of salicylates and lower the blood salicylate level. This can be done quite effectively by giving a lower dose of salicylates.

Phenacetin is another safe and innocuous analgesic, in fact some regard it as the safest of all synthetic analgesics, and it is much to be preferred to acetanilide although the analgesic action of these two drugs is almost identical. On the other hand, the leading members of the pyrazol group have a much more pronounced analgesic action than phenacetin, but unfortunately they have a tendency to produce agranulocytosis. Amido- pyrin was the most widely prescribed drug in this group, and its spasmolytic powers enhanced its usefulness, but its neutropenic tendencies have rightly caused it to fall into disfavour. Saridone contains a pyrazol derivative but is about twice as effective as amidopyrine in the same dosage; no cases of agranulocytosis following its use have been described although it has now been widely used for many years. Saridone may occasionally give rise to subjective feelings of dizziness about ten minutes after being taken; the patient should therefore be warned and treatment should be started with a small dose.

Tab. codeine co. is unfortunately constipating and thus may be contra-indicated in some cases, though this efficacious compound is otherwise innocuous.

Williams and Streeten (1950) have shown that morphine and amidone given to dogs in doses equivalent to those used clinically have a marked inhibiting effect on intestinal propulsion, while pethidine, even given in much larger doses, does not interfere with intestinal propulsion.

Pethidine produces side effects in about 25 per cent. of individuals. It causes a definite fall in blood pressure and should not be used where this might be undesirable, as in coronary thrombosis though here, since it may almost abolish the refles coronary artery spasm, it can be useful. On the other hand it has no practical effect on respiration although Prescott et al. (1949) claims that it has $\vec{a}$ depressant action on respiratory response to carbon dioxide. The commonest subjective sensation produced by pethidine is giddiness, naturally most noticeable in the ambulant patient; occasionally there may be nausea or even vomiting. On the whole this drug is remarkably free from side effects; it is a pity that it is not so active when given orally as it is by injection.

Some of the so-called undesirable side effects of morphine are of great value in certain cases. Its constipating tendencies, for instance, are useful in dealing with chronic organic diarrhoeas, and its hypnotic action valuable in quieting the restless pain of coronary thrombosis, but neither of these two attributes are particularly welcome in the management of ambulant cases of chronic pain. It $\frac{D}{0}$ causes nausea and vomiting in the occasional patient but there are very few who cannot take the or drug for this reason. We have seen only one $N$ patient completely intolerant of morphine in the 소 last five years.

Its depressant action on the respiratory centre must cause discrimination in its use, but even this has its place in the treatment of chronic cough. $\stackrel{\oplus}{\rightarrow}$ While the pain of smooth muscle spasm is relieved 0 by morphine, the actual muscular spasm remains 
unaffected or becomes more intense; on these grounds it should be avoided in the treatment of the colics. Pethidine is in general a vastly superior drug for this purpose and much more satisfactory clinically than either morphine or omnopon and atropine. But it is often preferable, in the final stage of a chronic fatal disease, to have somnolence rather than a questioning wakefulness; both the patient and the attendants prefer a peaceful end and morphine and omnopon are ideal for this purpose.

Amidone and phenadoxone at first promised to supersede other analgesics. So far they have not gained such a place and this may be due to the intolerance to them shown by some patients, particularly older people. Amidone is a respiratory depressant (Glazebrook, loc. cit.), although not quite to the same extent as morphine. They may cause subjective feelings of nausea and actual vomiting. The vomiting following the administration of amidone may last for as long as eight hours and cause severe prostration, and introducing a patient to the drug by means of subtherapeutic doses does not always obviate this unfortunate tendency.

\section{Indications for Analgesics}

From a study of the side effects produced by the various analgesics, it becomes clear that definite indications exist in most cases for the use of one or other of them, either because it is desired to use the side effects therapeutically or to avoid them.

Thus aspirin in ordinary analgesic dosage has no drawbacks with the average patient, and high dosage can be given to cases of acute rheumatic fever as there is evidence that the hypoprothrombinaemia so produced is of therapeutic value (Glazebrook and Cookson, loc. cit.).

Where something rather stronger than aspirin is needed tab. codeine co. is a reliable and satisfactory preparation. Unfortunately its liability to cause constipation may not suit some patients and in these cases a pyrazol derivative such as amidopyrine or saridone may be tried.

All of the more potent analgesics are liable to cause habit formation and addiction, and they should therefore be avoided if there is any question of this occurring except in cases of incurable malignant disease.

Pethidine, because of its spasmolytic properties and the mildness of its subjective side effects, is undoubtedly the drug of choice for colicky pains. It is rapidly dissipated in the body and maximal dosage may be given four hourly. It has gained a well-merited place in the management of labour. It is useful as a follow-on to morphine in postoperative treatment. Its hypotensor effect may be made use of in the treatment of hypertensive headache. It is a valuable drug in the treatment of chronic osteo-arthritis in the elderly when this $\frac{T}{D}$ condition has progressed beyond the help of other $\cong$

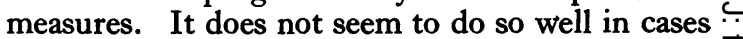
of chronic malignant disease and is unfortunately not so active when given by mouth as it is by in- $\vec{O}$ jection. It should not lightly be given to younger $\frac{}{0}$ people with chronic disease. One often sees it $\frac{\bar{\sigma}}{\bar{s}}$ prescribed for peptic ulcer cases for instance $\mathbb{\nabla}$ although it is a drug liable to cause habit formation.

We hesitate to prescribe some of the new $\overrightarrow{0}$ analgesics in cases of acute disease because we have $\overrightarrow{\mid}$ seen the occasional patient so distressed by vomit- $\stackrel{\omega}{\sigma}$ ing after these drugs. Although experimentally $\vec{D}$ they have been shown to possess an analgesic 3 potency equal to morphine, clinically they some- in times fail when morphine is successful. Never- of theless they have a well-defined place in the $\stackrel{\mathcal{C}}{\mathcal{C}}$ therapy of pain, that is in the case of the ambulant in patient with chronic incurable disease in whom the ${ }_{0}^{\circ}$ danger of addiction may be ignored, and where it is 은 desirable to avoid the somnolence and constipation $\rightarrow$ caused by morphine. Many of these patients take $Z$ the drugs well and will be remarkably grateful for the prescription of them.

We are left with many cases in which morphine or its total alkaloids, used in one form or anothef for 2,000 years, remains the drug of choice in spi $\vec{E}$ of the alternatives the chemists have produce $\overline{5}$. Nothing has been found to equal its effectiveness in pre- or post-operative medication, to calm the wounded, to quieten the agony of coronary thrombosis and to ease the passage of the tired and dying patient.

\section{Summary}

The perfect analgesic with maximal therapeutic effect and minimal side actions, particularly in respect to addiction, has yet to be discovered, but chemists have opened a wide field for in- 3 . vestigation by researches stemming from the original isolation of the morphine alkaloid in 1805.3 These researches have been concerned with the $\delta$ elucidation of the chemical structure of morphine, the preparation of more active derivatives and the $\frac{9}{7}$ total synthesis of compounds possessing true $\rightarrow$ analgesic activity. Of the thousands of com- 을 pounds so produced three have been found useful $\bar{\sim}$ enough to make generally available-pethidine, or amidone and phenadoxone. These three com- $\tilde{O}$ pounds at first sight are not alike but, when atomic ${ }_{\omega}^{N}$ models are made, a close resemblance is seen be- $\bar{O}$ tween them and the mother substance morphine. 6

It may be that potent analgesic action cannot be $\overparen{\Phi}$ achieved without liability to addiction, and it ? certainly seems true for any substance which has ${ }^{\circ}$ so far been developed from morphine. 


\section{BIBLIOGRAPHY}

BERGEL, F., and MORRISON, A. L. (1948), Quart. Rev. Chem. Soc., ii, No. 4,349 .

B.I.O.S. FINAL REPORT (1945), 116, No. 24, 52.

COMMISSION ON NARCOTIC DRUGS (1948), Extract from 'Report to the Economic and Social Council on the Second Session of the Commission.'

DAVIES, O. L., RAVENTOS, J., and WALPOLE, A. L. (1946), Brit. F. Pharmacol., I, 255.

EISLEB, O., and SCHAUMANN, O. (1939), Dtsch. med. Wschr. 65. 967.

ELliOTT, H. W. (1947), Fed. Proc., 6, Part ii, 327.

FOURNEAU (1938), Chim. et Ind., 39, 1043.

GLAZEBROOK, A. J. (1949), Edinb. Med. F., 56, 206.

GLAZEBROOK, A. J., and BRANWOOD, A. W. (1945), Lancet, ii, 528 .

GLAZEBROOK, A. J., and COOKSON, B. (1947), Edinb. med. F., 44, 193 .

HARDY, J. D., WOLFF, H. G., and GOODELL, H. (1940), f. clin. Invest., 19, 649.

HEWER, A. J. H., and KEELE, C. A. (I948), Lancet, ii, 683.

MACLAGAN, T. J. (1876), Lancet, $i, 383$.
PARKER, C. S., and WRIGLEY, F. (1947), Lancet ii, 223.

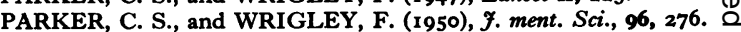
PERLSTEIN, M. A. (1947), Э. Amer. Med. Ass., 135, 633. POLONIO, P. (1947), Lancet, i, 592.

PRESCOTT, F., et al. (1949), Lancet, i, 340.

ROBSON, J. M., and KEELE, C. A. (1950), 'Recent Advances in Pharmacology,' Churchill.

SAHLI, H. (1909), Therapeutische Monatshefte fgg., 23, H I, S 1-6. SCOTT, C. C., ROBINS, E. B., and CHEN, K. K. (1946), Ssience, I04, 587.

SERTURNER (1806), f. d. Pharm. f. Aerzte. Apoth. u. Chem., 14, 49. STRAUB (I91 I), Dtsch. med. Wschr., 37, 1462.

WILLIAMS, E. M. V., and STREETEN, D. H. P. (1950), Lancet ii, 213. WILSON, W. M., and HUNTER, R. B. (1948), Brit. Med. F., $\vec{\circ}$

WREN, SIR C., and BOYLE, R. (1656), Quoted from ' History of Medicine,' Garrison, 4th edition, 1945, p. 273.

WRIGLEY, F. (1948), West London Hospital, Dept. of Rheum. Dis., Annual Report, p. 28.

ZAGER, L. L., ft al. (1949), f. Lab. clin. Med., 34, 1530.

\section{Dr. SHEILA SHERLOCK : Cirrhosis of the Liver}

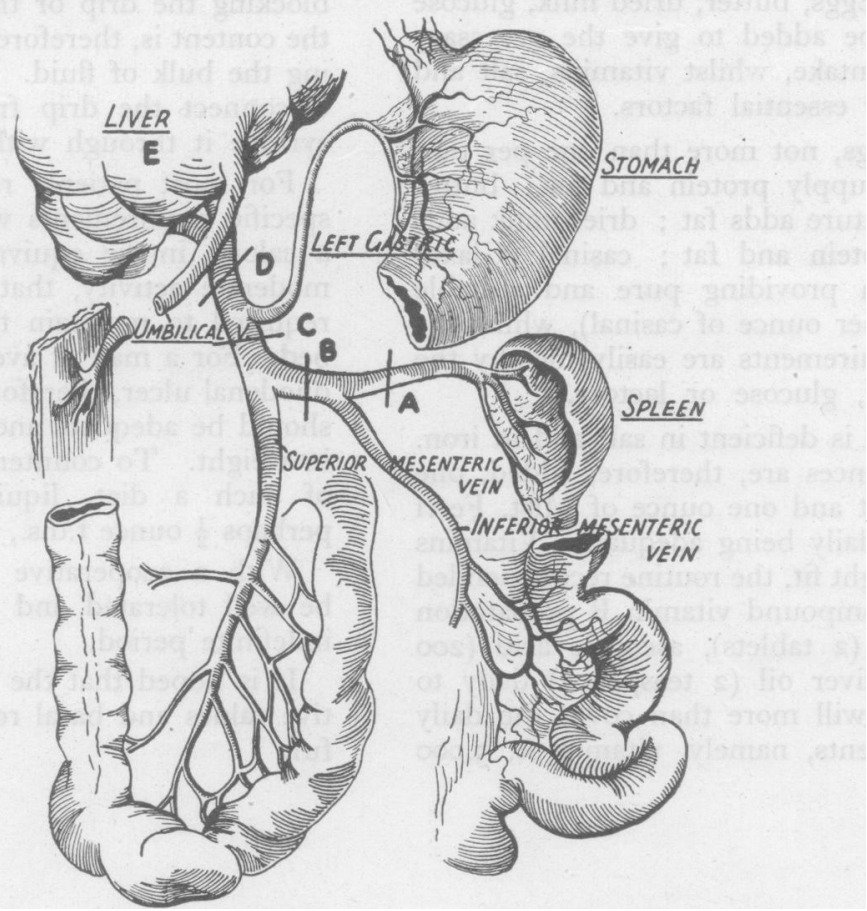

FIG. I I.-The effects of obstruction to the portal venous system.

Site of Obstruction

A Splenomegaly.

B Splenomegaly, haemorrhoids.

C Splenomegaly, haemorrhoids, flatulent dyspepsia, delayed water absorption from the intestines.

D Splenomegaly, haemorrhoids, flatulent dyspepsia, delayed water absorption, gastric and oesophageal varices.

E Splenomegaly, haemorrhoids, flatulent dyspepsia, delayed water absorption, gastric and oesophageal varices, engorgement of the anterior abdominal wall veins around the umbilicus. 